\title{
Giardia duodenalis extracellular vesicles regulate the proinflammatory immune response in mouse macrophages in vitro via the MAPK, AKT and NF-KB pathways
}

Panpan Zhao ${ }^{1,3+}{ }^{+} \mathrm{Lili}^{\mathrm{Cao}}{ }^{1,2+}$, Xiaocen Wang ${ }^{1 \dagger}$, Jianhua $\mathrm{Li}^{1}$, Jingquan Dong ${ }^{1,3}$, Nan Zhang ${ }^{1}$, Xin $\mathrm{Li}^{1}$, Shan Li ${ }^{1}$, Min Sun ${ }^{1}$, Xichen Zhang ${ }^{1}$, Min Liang ${ }^{1}$, Xudong Pu ${ }^{1}$ and Pengtao Gong ${ }^{1^{*}}$ (D)

\begin{abstract}
Background: Giardia duodenalis is an extracellular protozoan parasite that causes giardiasis in mammals. The presentation of giardiasis ranges from asymptomatic to severe diarrhea, and the World Health Organization lists it in the Neglected Diseases Initiative. Extracellular vesicles (EVs) are a key mediator of intracellular communication. Although previous studies have shown that $G$. intestinalis can regulate a host's innate immune response, the role of $G$. intestinalis EVs (GEVs) in triggering a $G$. intestinalis-induced innate immune response remains to be further explored.
\end{abstract}

Methods: In this study, GEVs, G. intestinalis and GEVs + G. intestinalis were inoculated into macrophages, respectively. The transcription and secretion levels of proinflammatory cytokines, including interleukin (IL)-1ß, IL-6 and tumor necrosis factor alpha (TNF-a), were measured using real-time quantitative PCR (qPCR) and enzyme-linked immunosorbent assays (ELISAs). The phosphorylation levels of the MAPK, AKT and NF-KB signaling pathways in GEVstimulated mouse macrophages were examined using western blotting and immunofluorescence methods. The roles of activated pathways in the GEV-triggered inflammatory response were determined using inhibition assays, western blotting and ELISAs.

Results: The results showed that pretreatment with GEVs enhanced with G. intestinalis (GEVs + G. intestinalis) induced IL-1 $\beta$, IL-6 and TNF-a transcription and secretion from mouse macrophages compared to stimulation with either GEVs or $G$. intestinalis alone. Inoculation of mouse macrophages with GEVs upregulated the phosphorylation levels of the p38 MAPK, p44/42 MAPK (Erk1/2), AKT and NF-KB signaling pathways and led to the nuclear translocation of NF-KB p65. Blocking the activated p38, Erk and NF-KB signaling pathways significantly downregulated the secretion of proinflammatory cytokines, and blocking the activated AKT signaling pathway demonstrated reverse effects.

Conclusions: The results of this study reveal that GEVs can enhance G. intestinalis-induced inflammatory response levels in mouse macrophages through activation of the p38, ERK and NF-KB signaling pathways. The role of GEVs in regulating host cell immune responses may provide insights into exploring the underlying mechanisms in G. intestinalis-host interactions.

\footnotetext{
*Correspondence: gongpt@jlu.edu.cn

†Panpan Zhao, Lili Cao and Xiaocen Wang authors have contributed equally to this work

${ }^{1}$ Key Laboratory of Zoonosis, College of Veterinary Medicine, Jilin University, Changchun 130062, People's Republic of China

Full list of author information is available at the end of the article
}

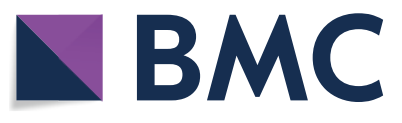

(c) The Author(s) 2021. This article is licensed under a Creative Commons Attribution 4.0 International License, which permits use, sharing, adaptation, distribution and reproduction in any medium or format, as long as you give appropriate credit to the original author(s) and the source, provide a link to the Creative Commons licence, and indicate if changes were made. The images or other third party material in this article are included in the article's Creative Commons licence, unless indicated otherwise in a credit line to the material. If material is not included in the article's Creative Commons licence and your intended use is not permitted by statutory regulation or exceeds the permitted use, you will need to obtain permission directly from the copyright holder. To view a copy of this licence, visit http://creativeco mmons.org/licenses/by/4.0/. The Creative Commons Public Domain Dedication waiver (http://creativecommons.org/publicdomain/ zero/1.0/) applies to the data made available in this article, unless otherwise stated in a credit line to the data. 
Keywords: Giardia duodenalis, Extracellular vesicles, Immune response, MAPK

\section{Background}

Giardia duodenalis is a protozoan parasite that colonizes the small intestine [1]. The ingestion of water or food contaminated with $G$. intestinalis cysts by susceptible mammalian hosts leads to giardiasis, especially in young children, with clinical presentations that range from no symptoms at all to severe diarrhea [2,3]. There are an estimated 280 million cases of diarrhea due to assemblages A and B of G. intestinalis-induced giardiasis annually [4]. Giardiasis has drawn public attention, and the World Health Organization lists it in the Neglected Diseases Initiative [5]. Innate immunity represents the first line of defense against pathogen invasion through the recognition of a vast array of pathogen-associated molecular patterns (PAMPs). A better understanding of vital PAMPs from G. intestinalis and exploration of its roles in the immune mechanisms of host resistance to infection with G. intestinalis will provide new insights into effective strategies against giardiasis.

Intracellular communication occurs via the delivery of biological molecules, including proteins, lipids and nucleic acids, by extracellular vesicles (EVs) [6]. EVs range in size from 30 to $1000 \mathrm{~nm}$ in diameter and are classified into microvesicles, exosomes, ectosomes and apoptotic bodies [7, 8]. Most cells, including immune cells, tumor cells and blood cells, secrete EVs that bind to pattern recognition receptors on target cells, and EVs may be used to deliver biological molecules into cells to activate intracellular signaling pathways and trigger immune responses $[9,10]$. Many parasites, including Trichomonas vaginalis, Trypanosoma brucei, Ascaris suum, Leishmania and Echinococcus multilocularis, secrete EVs to modulate host-pathogen communication [11-15]. Giardia intestinalis is an extracellular pathogen that adheres to the surface of enterocytes but does not enter these cells [1]. It releases various kinds of EVs, which are captured by human immature dendritic cells, and these EVs are also involved in G. duodenalis adhesion to enterocytes [16-18].

Macrophages are the most important and powerful phagocytic cells and are widely distributed in the tissues of mammals. These cells play roles in the elimination of invading pathogens [19]. Our previous study showed that mouse macrophages internalized G. duodenalis EVs (GEVs), which subsequently regulated the secretion of inflammatory cytokines [20]. Mitogen-activated protein kinase (MAPK) signaling pathways consist of several kinases, including p38 MAPK, extracellular signal-related kinase (ERK) and c-Jun-activated kinase (JNK). These pathways activate an orchestrated cascade, phosphorylate MAPK kinases, regulate cell proliferation and differentiation and control cell responses to cytokines and stress [21-23]. The nuclear transcription factors NFkappaB $(\mathrm{NF}-\mathrm{kB})$ or Rel proteins regulate the expression of sets of genes and may influence a variety of biological processes, such as innate immunity, adaptive immunity, inflammation and stress responses [24]. Insulin and a variety of growth and survival factors activate the PI3K/ Akt signaling pathway, which plays a critical role in controlling survival and apoptosis $[25,26]$. The interaction of immune response mechanisms between GEVs and macrophages requires further elucidation.

In study reported here we enriched GEVs and then examined the roles of these vesicles in the G. duodenalis-induced inflammatory response, detected the protein expression levels of the MAPK, AKT and NF- $\mathrm{KB}$ signaling pathways and then determined the roles of these activated pathways in GEV-induced inflammatory responses in mouse macrophages, with the ultimate aim to determine the role of GEV regulation in inflammatory immune response mechanisms.

\section{Methods \\ Animals}

The Animal Welfare and Research Ethics Committee of Jilin University approved all of the mouse experiments (IACUC Permit Number: pzpx20190929065). Female C57BL/6 mice (6-8 weeks) were purchased from the Changsheng Experimental Animal Center (Anshan, China), fed sterilized food and water ad libitum and housed in feeding cages kept under a 12/12-h light/dark cycle.

\section{Parasites and GEVs}

Giardia duodenalis trophozoites (WB strain clone C6, ATCC30957; American Type Culture Collection, Manassas, VA, USA) were grown for 48-72 $\mathrm{h}$ in modified TYIS-33 medium with 12.5\% fetal bovine serum (FBS; Every Green, Zhejiang, China) and 0.1\% bovine bile (SigmaAldrich, Merck KGaA, Burlington, MA, USA) at $37{ }^{\circ} \mathrm{C}$ under microaerophilic conditions. Confluent trophozoites were passaged by placing the tubes on ice for $20 \mathrm{~min}$ and rubbing the tubes 50-100 times at 10-min intervals. The suspended trophozoites were centrifuged at $2000 \times g$ for $8 \mathrm{~min}$ and resuspended in fresh medium at a final concentration of $1 \times 10^{8}$ parasites $/ \mathrm{ml}$.

GEVs were prepared as previously described with slight modifications [16-18, 27]. Specifically, the G. duodenalis 
trophozoites were diluted to $1 \times 10^{6}$ parasites $/ \mathrm{ml}$ and cultured for $12 \mathrm{~h}$ in modified TYI-S-33 medium with $12.5 \%$ exosome depleted of fetal bovine serum (Biological Industries, Beit HaEmek, Israel). GEVs in culture supernatants were purified through gradient centrifugation at $2000 \times g$ for $10 \mathrm{~min}$ and at $10,000 \times g$ for $45 \mathrm{~min}$ followed by ultracentrifugation at $100,000 \times g$ for $60 \mathrm{~min}$ after first being filtered through a $0.22-\mu \mathrm{m}$ sterilized PES membrane (Merck Millipore, MilliporeSigma, Burlington, MA, USA). The pellets were then resuspended in $200 \mu \mathrm{l}$ of sterilized phosphate-buffered saline (PBS) after two washes. The protein concentrations were quantified using a BCA protein assay kit (Thermo Fisher Scientific, Waltham, MA, USA).

\section{Preparation of mouse peritoneal macrophages}

After an acclimatization period of $>7$ days, the mice were inoculated intraperitoneally with $2.5 \mathrm{ml}$ of $2.98 \%$ Difco Fluid Thioglycollate medium (BD, Franklin Lakes, NJ, USA), then fed for 3-4 days. The mice were then euthanized, and the peritoneal cavities were flushed twice with $10 \mathrm{ml}$ of cold PBS. Cell suspensions were centrifuged at $1000 \times \mathrm{g}$ for $10 \mathrm{~min}$, washed twice in $5 \mathrm{ml}$ of RPMI 1640 medium (Biological Industries) and diluted in RPMI 1640 medium with $10 \%$ FBS (Biological Industries) to a final concentration of $1.5 \times 10^{6}$ cells $/ \mathrm{ml}$. The cells were transferred to 6 -well cell culture plates $\left(4.5 \times 10^{6}\right.$ cells/well $)$ and allowed to settle for 4-6 h. The medium was replaced with fresh culture medium, and the cells were cultured for $12 \mathrm{~h}$ at $37{ }^{\circ} \mathrm{C}$ with $5 \% \mathrm{CO}_{2}$. Cell purity was verified using flow cytometry detection of the CD11b marker (>98\%).

\section{Cell line culture and establishment of the stimulation model}

The THP-1 human monocytic cell line (ATCC TIB202; American Type Culture Collection) was cultured in RPMI-1640 medium supplemented with $10 \%$ FBS in a T75 flask and maintained at $37{ }^{\circ} \mathrm{C}$ and $5 \% \mathrm{CO}_{2}$. The cells were transferred into 12 -well cell culture plates $\left(1.5 \times 10^{6}\right.$ cells/well $)$ and induced to differentiate with $50 \mathrm{nM} 4 \alpha$-phorbol 12-myristate 13-acetate-PMA (SigmaAldrich) for $48 \mathrm{~h}$. After washing three times with PBS, the THP- 1 cells were cultured in complete RPMI-1640 medium for stimulation experiments.

Mouse macrophages or THP-1 cells were prestimulated with $25 \mu \mathrm{g} / \mathrm{ml} \mathrm{GEVs}$ for $1 \mathrm{~h}$ and then infected with $1.5 \times 10^{6} \mathrm{G}$. duodenalis/ml for $18 \mathrm{~h}$ in a noncontact system. An equal volume of a PBS-treated group was used as a negative control. The GEV $(25 \mu \mathrm{g} / \mathrm{mL})$-treated group or a noncontact system for the G. duodenalis $\left(1.5 \times 10^{6}\right.$ parasites $/ \mathrm{ml}$ )-treated group was used as a positive control group, as described in our previous study [20]. Briefly, a $0.4-\mu \mathrm{m}$-sized Transwell insert (Corning Inc., Corning, NY, USA) was added to cell plates that were previously coated with cultured macrophages, and G. duodenalis was inoculated onto the membrane of the Transwell apparatus.

\section{Real-time quantitative PCR assays}

Total RNA was extracted from infected mouse macrophages with TRIzol reagent (Monad; Wuhan, China) after $12 \mathrm{~h}$ of incubation with GEVs. Purity and concentration were verified $\left(\mathrm{OD}_{260 \mathrm{~nm}} / \mathrm{OD}_{280 \mathrm{~nm}}=1.8-2.0\right)$ with a Nanodrop ND-2000 spectrophotometer (Thermo Fisher Scientific). First-strand cDNA was synthesized via reverse transcription with MonScript RTIII Super Mix with dsDNase (Two-Step) (Monad). Primers for proinflammatory cytokines and housekeeping genes were synthesized by Comate Bioscience Company Limited (Changchun, China) (see Table 1 for primer sequences). Gene transcription levels were detected using real-time quantitative PCR (qPCR) assays performed on a LightCycler 480 II platform (Roche Diagnostics GmbH, Mannheim, Germany) with the MonAmp SYBR Green qPCR Mix (None

Table 1 Primer sequences used for the real-time quantittive PCR assays

\begin{tabular}{|c|c|c|c|c|c|c|}
\hline Target & Genebank number & Primer sequences ( $5^{\prime}$ to $\left.3^{\prime}\right)$ & Product size (bp) & $\begin{array}{l}\text { Primer length } \\
(\mathrm{nt})\end{array}$ & $\begin{array}{l}\text { Cross intron } \\
\text { length (nt) }\end{array}$ & Primer site \\
\hline \multirow[t]{2}{*}{$\| L-1 \beta$} & NM_008361 & F: AGGAGAACCAAGCAACGACA & 241 & 20 & 1545 & $582 \ldots 601$ \\
\hline & & R: CTCTGCTTGTGAGGTGCTGA & & 20 & & $822 \ldots 803$ \\
\hline \multirow[t]{2}{*}{ TNF-a } & NM_013693 & F: GACGTGGAACTGGCAGAAGA & 253 & 20 & 696 & $192 \ldots 211$ \\
\hline & & R: GGCTACAGGCTTGTCACTCG & & 20 & & $446 \ldots 427$ \\
\hline \multirow[t]{2}{*}{ IL-6 } & NC_000071 & F:TGCCTTCTTGGGACTGATGC & 216 & 20 & 1272 & $279 \ldots 298$ \\
\hline & & R: GCAAGTGCATCATCGTTGTTC & & 21 & & $1765 \ldots 1745$ \\
\hline \multirow[t]{2}{*}{ Actb } & NM_007393 & F: GCCATGTACGTAGCCATCCA & 240 & 20 & 455 & $391 \ldots 410$ \\
\hline & & R: ACGCACGATTTCCCTCTCAG & & 20 & & $630 \ldots 611$ \\
\hline
\end{tabular}


ROX; Monad). The assays were performed in a reaction mixture (total volume $20 \mu \mathrm{l}$ ) containing $10 \mu \mathrm{l}$ of $2 \times \mathrm{qPCR}$ Mix, $0.2 \mu \mathrm{M}$ of forward primer, $0.2 \mu \mathrm{M}$ of reverse primer, $1 \mu \mathrm{l}$ of cDNA diluted 20 -fold and nuclease-free water. The reaction program consisted of denaturation at $95{ }^{\circ} \mathrm{C}$ for $30 \mathrm{~s}$; amplification at $95{ }^{\circ} \mathrm{C} / 10 \mathrm{~s}, 60{ }^{\circ} \mathrm{C} / 30 \mathrm{~s}$ for 40 cycles (the fluorescence signal was read at this point); a default melting curve was used. Gene expression analysis was normalized to the expression of Actb (beta-actin), and the relative mRNA fold-change was calculated by the $2^{-\Delta \Delta \mathrm{Cq}}$ method, where $\Delta \mathrm{Cq}$ represents the $\mathrm{Cq}$ (proinflammatory cytokines) $-\mathrm{Cq}$ (Actb), and $\Delta \Delta \mathrm{Cq}$ represents the $\Delta \mathrm{Cq}$ (experimental group) $-\Delta \mathrm{Cq}$ (control group).

\section{Enzyme-linked immunosorbent assays}

Cell culture supernatants were collected $18 \mathrm{~h}$ after stimulation to detect secretion of the proinflammatory cytokines interleukin (IL)-1 $\beta$, IL- 6 and tumor necrosis factor alpha (TNF- $\alpha$ ) with commercial enzyme-linked immunosorbent assays (ELISA) kits (Invitrogen, Thermo Fisher Scientific, Carlsbad, CA, USA). According to the manufacturer's instructions, ELISA plates (Corning Inc.) were coated with capture antibodies (100 $\mu \mathrm{l} /$ well $)$ and incubated at $4{ }^{\circ} \mathrm{C}$ overnight. The plates were blocked with ELISA/ELISPOT diluent $(1 \times 200 \mu \mathrm{l} /$ well $)$ at room temperature (RT) for $1 \mathrm{~h}$ after being washed three times with wash buffer. Prepared twofold serial dilutions of standard samples and supernatant samples $(100 \mu \mathrm{l} /$ well $)$ were added to the plates and incubated overnight at $4{ }^{\circ} \mathrm{C}$. After five washes, detection antibodies $(100 \mu \mathrm{l} /$ well $)$ were added to the plates and incubated at RT for $1 \mathrm{~h}$. Streptavidin-horseradish peroxidase (HRP) or avidin-HRP (100 $\mu \mathrm{l} /$ well $)$ and a $1 \times$ TMB solution $(100 \mu \mathrm{l} /$ well $)$ were added to plates and incubated for $30 \mathrm{~min}$ and $15 \mathrm{~min}$, respectively. The reaction was stopped with the addition of a stop solution $(100 \mu \mathrm{l} /$ well $)$, following which the cells were washed seven times. The $\mathrm{OD}_{450 \mathrm{~nm}}$ values were measured on a microplate reader, and standard curves were generated. The $\mathrm{OD}_{450 \mathrm{~nm}}$ values of the samples were converted to protein concentrations.

\section{Western blot assays}

Cells were collected at $0,0.5,1,2$ and $4 \mathrm{~h}$ after GEV stimulation, and protein was extracted using RIPA lysis buffer (Solarbio, Beijing, China) supplemented with $100 \times$ protease inhibitor cocktail $(1 \% \mathrm{v} / \mathrm{v})$ and $10 \times$ phosphatase inhibitor complex III $(10 \% \mathrm{v} / \mathrm{v}$; Sangon, Shanghai, China). The lysis supernatants were quantified with a BCA protein assay kit. Protein samples were denatured by mixing with $6 \times$ protein loading buffer (TransGen, Beijing, China) and boiling for $10 \mathrm{~min}$. Equal amounts of protein samples $(20 \mu \mathrm{g} / \mathrm{well})$ were added to a $12 \%$ sodium dodecyl sulfate-polyacrylamide (SDS-PAGE) gel and separated by electrophoresis $(80 \mathrm{~V} / 1 \mathrm{~h}$ and $120 \mathrm{~V} / 1 \mathrm{~h})$ in Tris-glycine-SDS buffer. The protein samples were transferred to polyvinyl difluoride membranes $(0.45 \mu \mathrm{m}$, Merck Millipore) under conditions of $200 \mathrm{~mA} / 1.5 \mathrm{~h}$, and the membranes were blocked in 5\% skim milk (in TBST buffer) at RT for $2 \mathrm{~h}$ and incubated overnight with primary antibodies against p38 MAPK, phospho-p38 MAPK, p44/42 MAPK (Erk1/2), phospho-p44/42 MAPK (Erk1/2), AKT, phospho-AKT, IKK $\alpha$, IKK $\beta$, phospho-IKK $\alpha / \beta$,

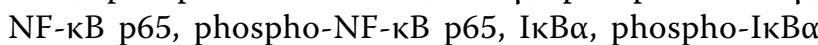
(1:1000; Cell Signaling Technology Inc., Danvers, MA, USA) and $\beta$-actin (1:5000; Proteintech, Wuhan, China) at $4{ }^{\circ} \mathrm{C}$ overnight. Membranes were washed three times with TBST ( $5 \mathrm{~min} /$ wash) and then incubated with HRPconjugated goat anti-rabbit immunoglobulin G (IgG) or horse anti-mouse IgG secondary antibody (1:1000, Cell Signaling Technology Inc.) at RT for $1 \mathrm{~h}$. The membranes were washed again with TBST and developed using an Omni-ECL Pico light chemiluminescence kit (Epizyme, Shanghai, China). The blots were visualized on a ChemiScope western blot imaging system (Clinx, Shanghai, China) and analyzed using ImageJ software.

\section{Inhibition assays}

To examine the roles of activated pathways in response to the GEV-induced proinflammatory immune reaction in mouse macrophages, cells were pretreated with an inhibitor of p38 MAPK (SB203580, $30 \mu \mathrm{M}$; MedChemExpress, USA), an inhibitor of ERK (SCH772984, $300 \mathrm{nM}$; MedChemExpress LLC, Monmouth Junction, NJ, USA), an inhibitor of AKT1/2/3 (MK-2206 2HCl, $5 \mu \mathrm{M}$; Selleck, Shanghai, China) or an inhibitor of IkB $\alpha$ phosphorylation (BAY 11-7082, $5 \mu \mathrm{M}$; Selleck) for $2 \mathrm{~h}$ before stimulation. Unpretreated cells were used as controls. The mRNA fold-change of the activated inflammatory cytokines was determined using $\mathrm{qPCR}$, and protein expression levels in the supernatants and cells were determined using ELISAs and western blotting assays, respectively.

\section{Immunofluorescence assays}

To observe the subcellular localization of NF- $\mathrm{kB}$ p65, $5 \times 10^{5}$ mouse macrophages previously coated onto 24-well plates were stimulated with $25 \mu \mathrm{g} / \mathrm{ml} \mathrm{GEVs}$ for 0 or $1 \mathrm{~h}$. The cells were gently washed three times with warm TBS, fixed in $4 \%$ paraformaldehyde (Biosharp, Beijing, China) for $10 \mathrm{~min}$ at RT, washed three times with TBS and permeabilized in $0.1 \%$ Triton X-100 at RT for $20 \mathrm{~min}$. The infected cells were blocked in 5\% BSA (in TBS) at RT for $2 \mathrm{~h}$, incubated overnight with 
rabbit anti-phospho-NF-кB p65 antibodies (1:100) at $4{ }^{\circ} \mathrm{C}$, washed three times in TBST and incubated with FITC AffiniPure goat anti-rabbit IgG $(\mathrm{H}+\mathrm{L})$ (1:100; EarthOx Life Sciences, Millbrae, CA, USA) antibodies in the dark for $1 \mathrm{~h}$ at $37^{\circ} \mathrm{C}$. After washing, cell nuclei were stained with $4^{\prime}$,6-diamidino-2-phenylindole and dihydrochloride (DAPI, $1 \mu \mathrm{g} / \mathrm{mL}$; Thermo Fisher Scientific). The subcellular localization of NF-kB p65 was observed under a fluorescence microscope (Olympus, Tokyo, Japan).

\section{Statistical analysis}

The results are presented as the mean \pm standard error of the mean (SEM) of three biological replicates. Differences between two groups were analyzed using the $t$ test with GraphPad Prism version 7.00 software (GraphPad Software Inc., La Jolla, CA, USA), and multiple groups were analyzed by one-way analysis of variance using SPSS version 22.0 software (SPSS-IBM Corp., Armonk, NY, USA). The homogeneity of variance of the data was analyzed with the Levene test, followed by a Bonferroni post hoc test (B). Graphs were generated in GraphPad Prism 7.00.
Significance is shown as $p<0.05, p<0.01$ and $p<0.001$, and n.s. indicates "not significant" $(p>0.05)$.

\section{Results}

GEVs enhanced G. duodenalis-induced proinflammatory cytokine production in macrophages

A previous study showed that G. duodenalis increased proinflammatory cytokine production in mouse macrophages [28]. To examine the role of GEVs in G. duodenalis-induced proinflammatory cytokine production, cells were pretreated with GEVs for $1 \mathrm{~h}$, then inoculated with G. duodenalis for measurement of proinflammatory cytokine expression. The negative and positive control groups were those treated with PBS + GEVs and PBS + G. duodenalis, respectively. The mRNA levels of proinflammatory cytokines were measured by qPCR (Fig. 1ac), and the protein secretion levels were measured with ELISAs (Fig. 1d-f). The results showed that both the GEV and G. duodenalis treatment groups exhibited significantly upregulated proinflammatory cytokine transcription and expression compared to the PBS-negative
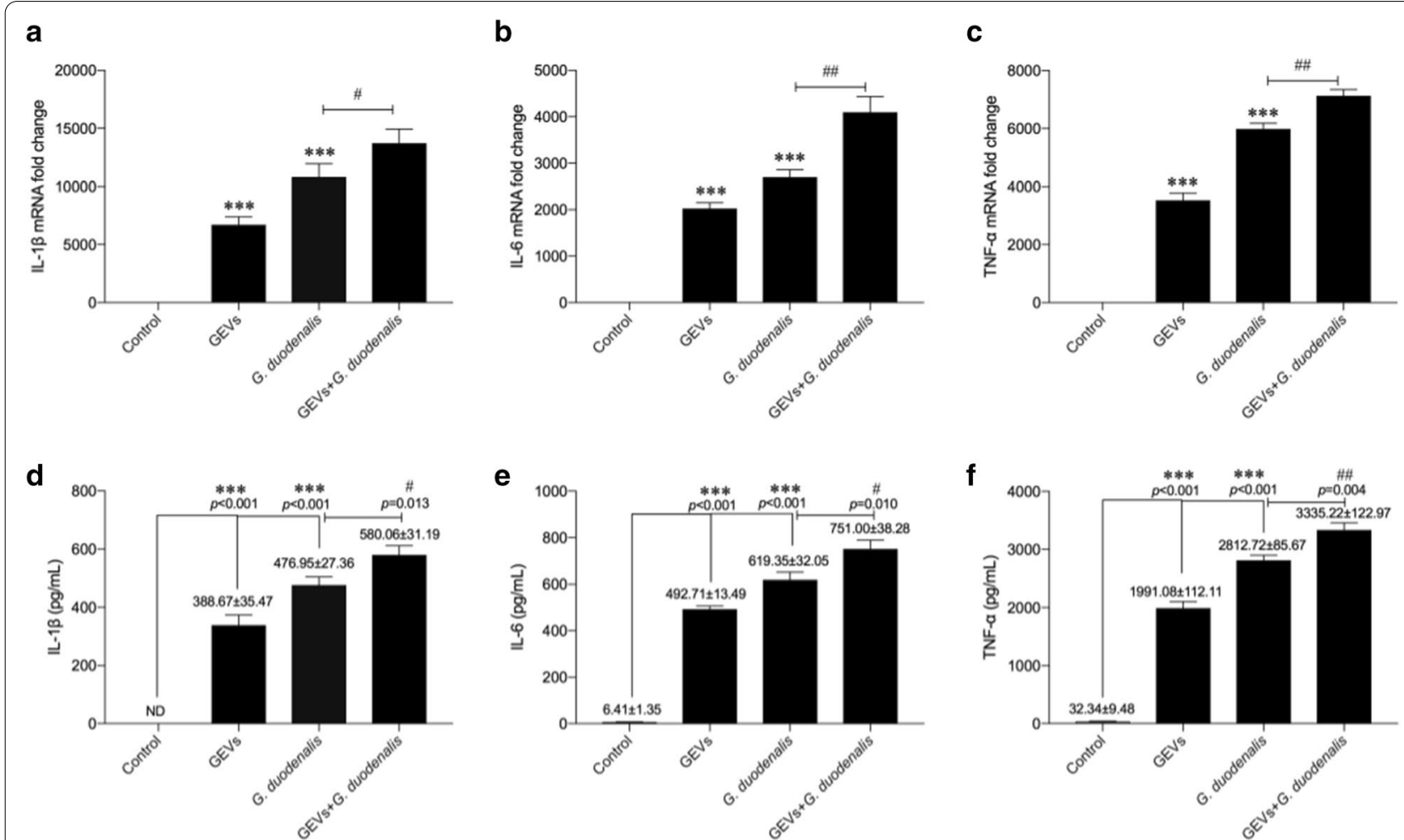

Fig. 1 Treatment with Giardia duodenalis extracellular vesicles (GEVs) enhanced proinflammatory cytokine transcription and secretion from mouse macrophages. Cells were inoculated with $25 \mu \mathrm{g} / \mathrm{ml} \mathrm{GEVs}, 1.5 \times 10^{6} \mathrm{G}$. duodenalis/ml, or GEVs + G. duodenalis. a-c Real-time quantitative PCR analysis of the transcription levels of the proinflammatory cytokines interleukin (IL)-1 $\beta$, IL- 6 and tumor necrosis factor alpha (TNF- $a$ ) in infected cells collected at $12 \mathrm{~h}$. $\mathbf{d}$-f Measurement of the secretion levels of proinflammatory cytokines in the supernatants collected $18 \mathrm{~h}$ after inoculation, by enzyme-linked immunosorbent assay (ELISA). The results are shown as the mean \pm standard error of the mean (SEM) of triplicate experiments. Asterisks indicate significance level of difference $v$ s the phosphate buffered saline control: ${ }^{*} p<0.05,{ }^{* *} p<0.01,{ }^{* * *} p<0.001$. Hashtag symbols indicate significance level of difference vs G. duodenalis-treated control: ${ }^{\#} p<0.05,{ }^{\# \#} p<0.01$ 
control group ( $\left.{ }^{* * * *} p<0.001\right)$. GEVs enhanced the G. duodenalis-induced inflammatory response of murine macrophages in the GEVs $+G$. duodenalis group compared to the G. duodenalis single-treatment group $\left({ }^{*} p<0.05\right.$ or ${ }^{* * *} p<0.01$ ). A similar trend was obtained with the stimulated THP-1 cells (Additional file 1: Fig. S1). Overall, these data demonstrate that GEVs induce proinflammatory cytokine production in macrophages and that GEVs can enhance the G. duodenalis-induced inflammatory response.

\section{GEVs activated the p38, ERK and AKT signaling pathways in mouse macrophages}

The MAPK and AKT signaling pathways are involved in different pathogen-triggered immune responses. To examine the roles of these signaling pathways in GEVinduced proinflammatory cytokine production, GEVs were inoculated into mouse macrophages, and the cells were collected at $0,0.5,1,2$ and $4 \mathrm{~h}$ after inoculation to measure the levels of total protein and phosphorylated protein in the MAPK and AKT signaling pathways using western blot assays. As shown in Fig. 2a, GEVs induced phosphorylation of $\mathrm{p} 38$, ERK and AKT. Protein gray values of phospho-p38/ $\beta$-actin, phospho-ERK/ $\beta$-actin and phospho-AKT $/ \beta$-actin were separately calculated using Excel (Microsoft Corp., Redmond, WA, USA) software, and differences were analyzed using SPSS software. The results showed that compared to the phospho-p38 levels at $0 \mathrm{~h}$, the $\mathrm{p} 38$ phosphorylation levels began to increase between 0.5 and $1 \mathrm{~h}(p>0.05)$, peaked at $2 \mathrm{~h}(p<0.01)$ after GEV inoculation and began to decrease at $4 \mathrm{~h}$. However, the levels remained higher at $4 \mathrm{~h}$ compared to those at $0 \mathrm{~h}$ ( $p>0.05$; Fig. $2 \mathrm{~b})$. The ERK phosphorylation levels increased with increasing inoculation time and peaked at $4 \mathrm{~h}$ compared to those at $0 \mathrm{~h}(p<0.001$; Fig. $2 \mathrm{c})$. The AKT phosphorylation levels slowly increased between 0.5 and $2 \mathrm{~h}(p<0.05$ or $p<0.01)$ and reached their highest levels at $4 \mathrm{~h}(p<0.001$; Fig. $2 \mathrm{~d})$. These results indicated that the p38, ERK and AKT signaling pathways were activated after the inoculation of GEVs into mouse macrophages.
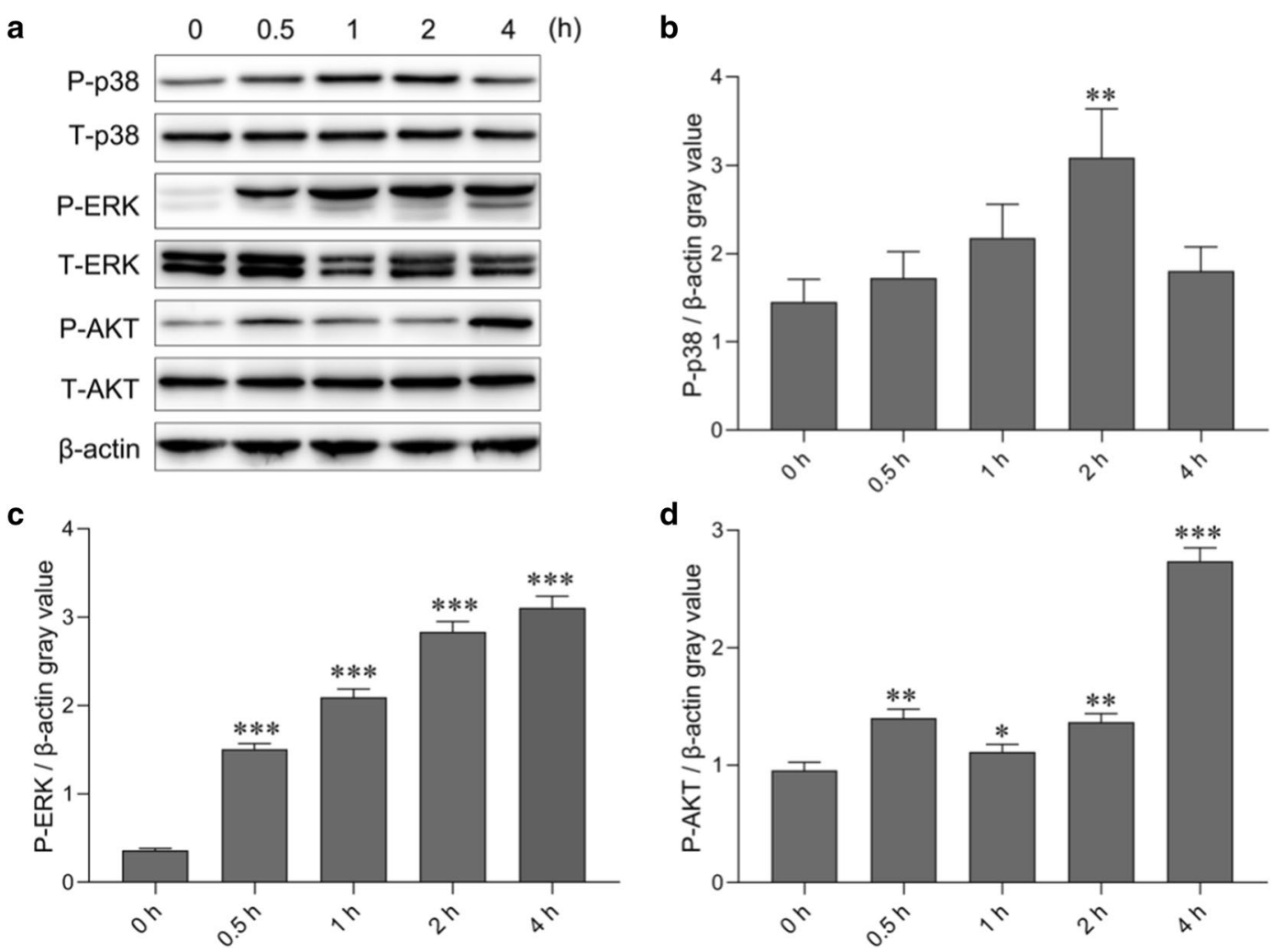

Fig. 2 p38 MAPK, ERK and Akt signaling pathway activation in response to GEV stimulation of mouse macrophages. a GEVs were inoculated into mouse macrophages, and cells were collected at the indicated time points for measurement of total protein and phosphorylated protein expression using western blotting. b Gray value analysis of phospho-p38/ $\beta$-actin. $\mathbf{c}$ Gray value analysis of phospho-ERK/ $\beta$-actin. $\mathbf{d}$ Gray value analysis of phospho-AKT/ $\beta$-actin. The results are shown as the mean \pm SEM of triplicate experiments. Significant differences vs $0-h$ control: ${ }^{*} p<0.05$, ${ }^{* *} p<0.01,{ }^{* * *} p<0.001$ 
GEVs enhanced proinflammatory cytokine production through phosphorylation of p38 and ERK

To examine the roles of the activated p38 and ERK signaling pathways in GEV-induced proinflammatory cytokine production, inhibitors of p38 MAPK-SB203580 and ERK-SCH772984 were added separately to mouse

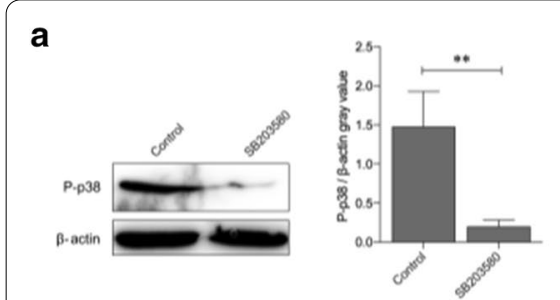

d

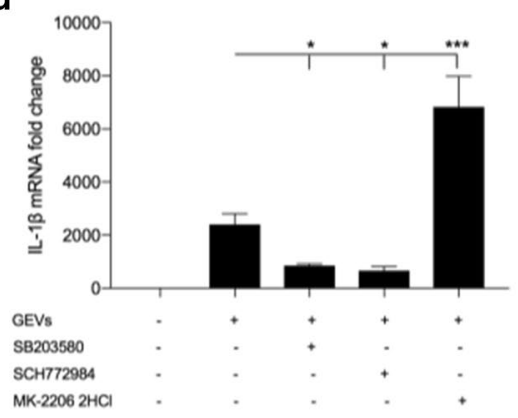

g

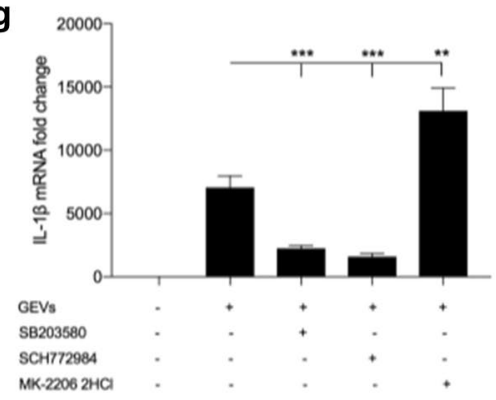

j

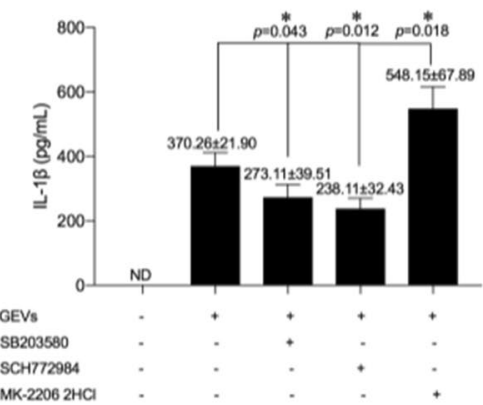

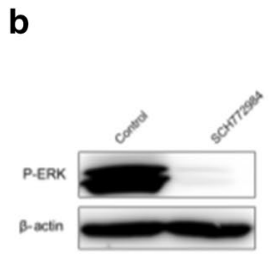

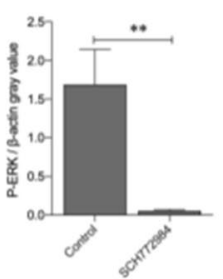

e

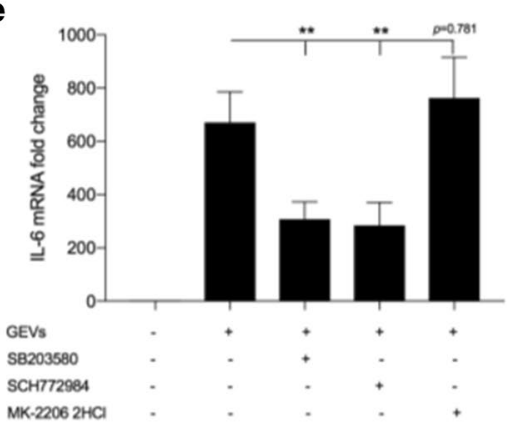

f
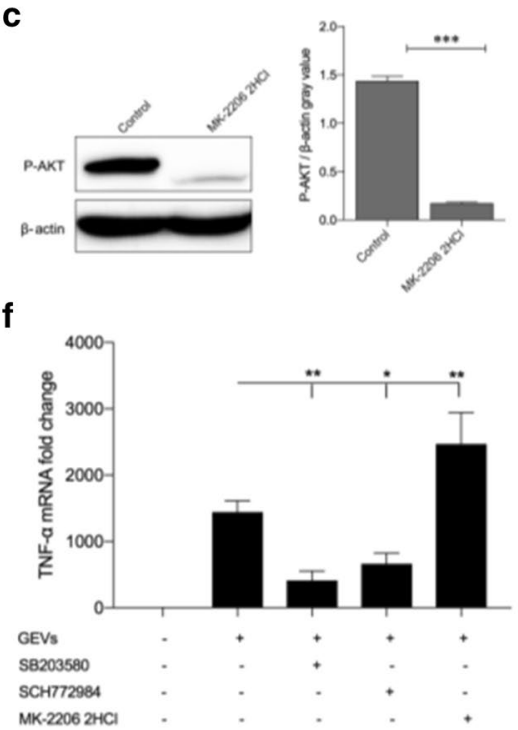

h
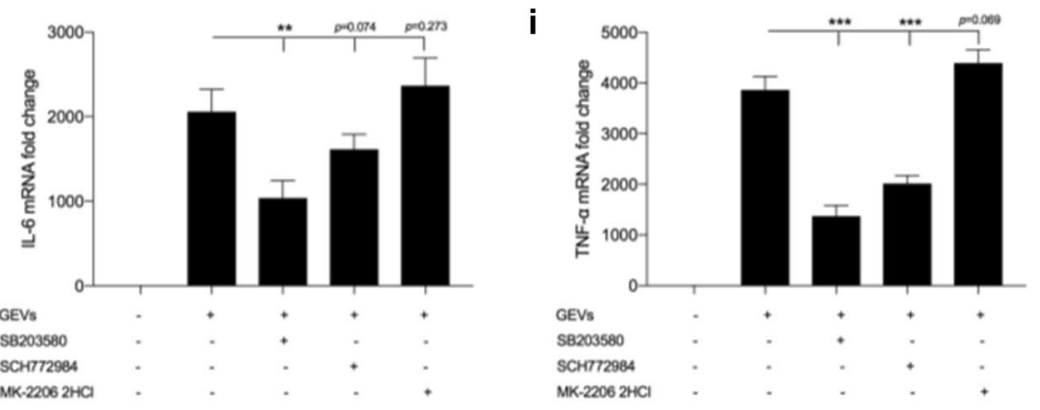

$\mathbf{k}$

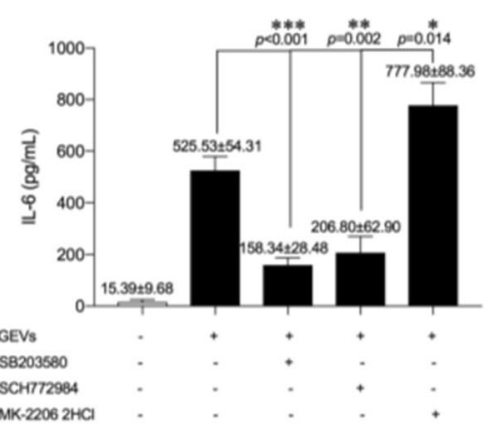

I

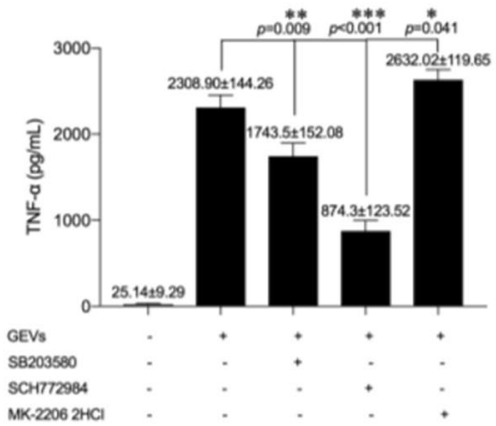

Fig. 3 GEVs regulated proinflammatory cytokine transcription and secretion through the p38 MAPK and ERK signaling pathways in a positive feedback manner and the Akt signaling pathway in a negative feedback manner. Mouse macrophages were pretreated with the p38 MAPK inhibitor

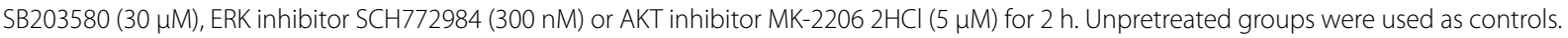
The inhibited cell groups were inoculated with GEVs for 2, 4 and $4 \mathrm{~h}$. a-c The phosphorylated protein expression levels of p38, ERK and AKT were measured using western blotting, and the gray values of phosphorylated protein/ $\beta$-actin were calculated using ImageJ software. $\mathbf{d}$-f Levels of proinflammatory cytokine transcription levels in cells collected $6 \mathrm{~h}$ after inoculation were detected using real-time quantitative PCR assays (qPCR). $\mathbf{g}$-i Levels of proinflammatory cytokine transcription levels in cells collected $12 \mathrm{~h}$ after inoculation were detected using qPCR assays. $\mathbf{j}-\mathbf{I}$ Levels of proinflammatory cytokine protein secretion levels were detected in supernatants collected $18 \mathrm{~h}$ after inoculation using ELISAs. The results show the mean \pm SEM of triplicate experiments. Signficant differences vs noninhibitor treatment control: ${ }^{*} p<0.05,{ }^{* *} p<0.01,{ }^{* * *} p<0.001$ 
macrophages, followed by inoculation of GEVs after pretreatment with inhibitors for $2 \mathrm{~h}$. At 2 or $4 \mathrm{~h}$ after inhibitor treatment, the cells were collected for separate measurement of the protein levels of phospho-p38 and phospho-ERK. Cells or cell culture supernatants were collected 12 and $18 \mathrm{~h}$ after treatment, respectively, for measurement of inflammatory cytokine expression. As shown in Fig. 3a, b, the phosphorylation levels of p38 and ERK were successfully inhibited at 2 and $4 \mathrm{~h}$, respectively. The mRNA levels of inflammatory cytokines were significantly downregulated after pretreatment with SB203580 or SCH772984 $(p<0.05, p<0.01$ or $p<0.001)$ except for IL-6 at $12 \mathrm{~h}$, which was slightly reduced $(p>0.05)$ after pretreatment with SCH772984 compared with that in the "no inhibitor" pretreatment groups (Fig. 3d, e, g, h). The ELISA results showed that pretreatment with SB203580 or SCH772984 slightly decreased IL- $1 \beta$ secretion $(p<0.05)$ and dramatically reduced the secretion of IL- 6 and TNF- $\alpha(p<0.01$ and $p<0.001$, respectively) (Fig. 3j-l). Inhibition assays revealed that GEVs regulated proinflammatory cytokine production through phosphorylation of p38 and ERK in a positive feedback manner.

\section{GEVs inhibited proinflammatory cytokine production through phosphorylation of AKT}

To examine the role of the activated AKT signaling pathway in the GEV-induced inflammatory response, cells were pretreated with the AKT inhibitor MK-2206 $2 \mathrm{HCl}$ for $2 \mathrm{~h}$ then stimulated with GEVs. The protein level of phospho-AKT in the infected cells was determined $4 \mathrm{~h}$ after GEV treatment using western blotting, and mRNA levels of inflammatory cytokines in infected cells were measured using qPCR $12 \mathrm{~h}$ after GEV treatment. The protein levels of inflammatory cytokines from infected cells were detected via ELISAs $18 \mathrm{~h}$ after GEV treatment. The levels of AKT phosphorylation were significantly downregulated in the $\mathrm{MK}-22062 \mathrm{HCl}$ pretreatment group compared with those in the untreated group $(p<0.001$; Fig. $3 c)$. The mRNA levels of IL- $1 \beta$ mRNA were dramatically increased compared with that in the untreated group $(p<0.01$ or $p<0.001)$. The levels of IL- 6 and TNF- $\alpha$ were upregulated, albeit not significantly $(p>0.05)$ except for TNF- $\alpha$ at $6 \mathrm{~h}$, which was markedly enhanced compared to the "no inhibitor" pretreatment group (Fig. 3d-f, g-i). The results of the ELISAs for proinflammatory cytokine secretion showed a significantly increasing trend after cell pretreatment with MK-2206 $2 \mathrm{HCl}(p<0.05$; Fig. $3 \mathbf{j}-1)$. These results demonstrated that GEVs regulated proinflammatory cytokine production via the phosphorylation of AKT in a negative feedback manner.

\section{GEVs activated NF-KB signaling pathways in mouse macrophages}

NF- $\kappa \mathrm{B}$ is a nuclear transcription factor that regulates the expression of proinflammatory cytokines. To determine whether the NF- $\mathrm{kB}$ signaling pathway was activated after the inoculation of mouse macrophages with GEVs, cells were collected $0,0.5,1,2$ and $4 \mathrm{~h}$ after GEV inoculation for the measurement of total and phosphorylated protein levels of $\mathrm{p} 65$, IKK $\alpha$, IKK $\beta$ and I $\mathrm{I} B \alpha$ by western blot assays, and the location of NF- $\mathrm{kB}$ p 65 was observed with immunofluorescence staining $1 \mathrm{~h}$ after inoculation with GEVs. The localization results showed that NF- $\mathrm{kB}$ p65 primarily existed in the cytoplasm of the untreated cells and that most NF-kB p65 was transferred to the cell nucleus and colocalized with the nucleus $1 \mathrm{~h}$ after mouse macrophage inoculation with GEVs (Fig. 4a). The phosphorylation levels of NF- $\kappa B$ p65, ІкB $\alpha$ and IKK $\alpha \beta$ in the infected cells varied during the initial $4 \mathrm{~h}$ of monitoring (Fig. $4 \mathrm{~b}$ ). The gray values of phospho-p65/ $\beta$-actin remained unchanged at $0.5 \mathrm{~h}(p>0.05)$, began to increase between 1 and $2 \mathrm{~h}(p<0.05$ or $p<0.01)$, then decreased at $4 \mathrm{~h}(p>0.05$; Fig. $4 \mathrm{c})$. The gray values of phosphoIк $B \alpha / \beta$-actin dramatically increased during the initial stimulation stage, as measured at $0.5 \mathrm{~h}(p<0.001)$, then returned to normal expression levels between 1 and $4 \mathrm{~h}$ $(p>0.05$; Fig. $4 d)$. The gray values of phospho-IKK $\alpha \beta / \beta$ actin markedly increased to high levels at $0.5 \mathrm{~h}$ and lasted for $4 \mathrm{~h}(p<0.05$ or $p<0.01$; Fig. $4 \mathrm{e})$. These data demonstrated that the NF- $\mathrm{kB}$ signaling pathway was activated after mouse macrophage inoculation with GEVs.

\section{GEVs enhanced proinflammatory cytokine production via phosphorylation of IKBa}

The translocation of NF-kB p65 was primarily due to the degradation of total $I_{\kappa} B \alpha$. To examine the influence of NF- $\mathrm{kB}$ on the GEV-induced inflammatory response, an inhibitor of $\mathrm{I} \kappa \mathrm{B} \alpha_{\alpha}$ phosphorylation, BAY 11-7082, was used to inhibit $\mathrm{I} \kappa \mathrm{B} \alpha$ degradation. The western blot assay results showed that the expression levels of phospho-I $\kappa \mathrm{B} \alpha$ were almost completely inhibited $(p<0.01$; Fig. 5a). The mRNA and secretion levels of inflammatory cytokines were measured using qPCR and ELISAs, respectively. As shown in Fig. 5b-j, the inflammatory response was significantly inhibited compared with that in infected cells without BAY 11-7082 pretreatment $(p<0.01$ or $p<0.001)$. Overall, these results indicated that the NF- $\mathrm{KB}$ signaling pathway regulated the GEV-induced inflammatory response in a positive feedback manner.

\section{Discussion}

Increasingly more attention is focusing on G. duodenalis-triggered diarrheal diseases, especially in developing countries, also driven by the increasing resistance to 
a
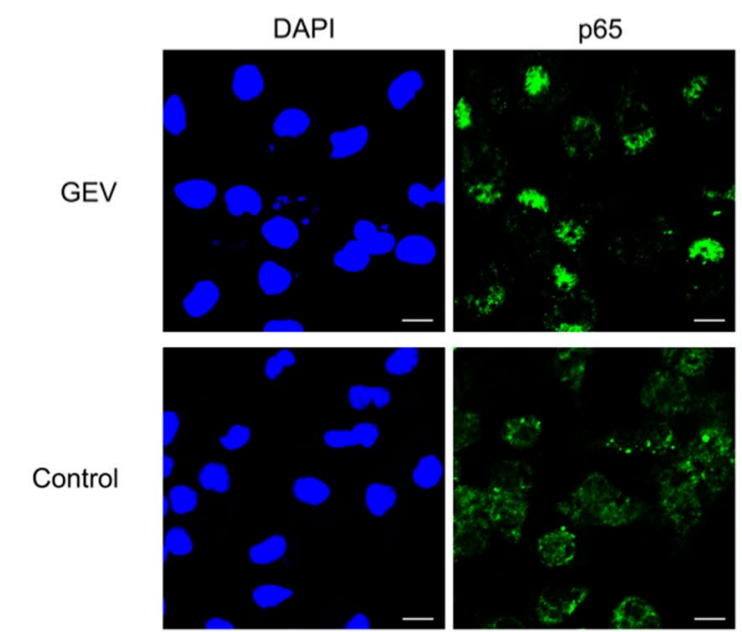

(h)

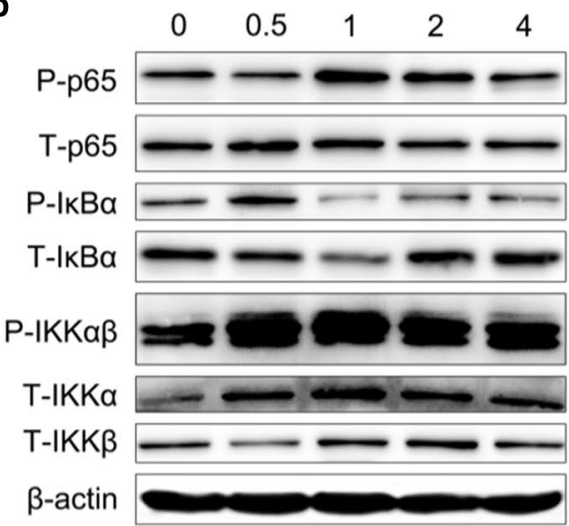

d

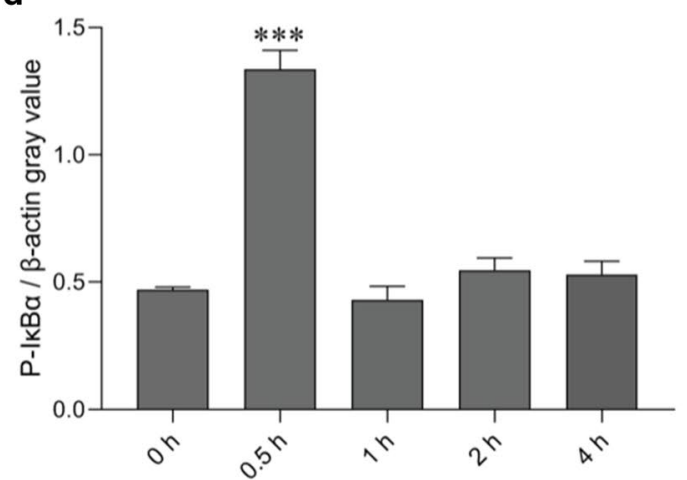

c

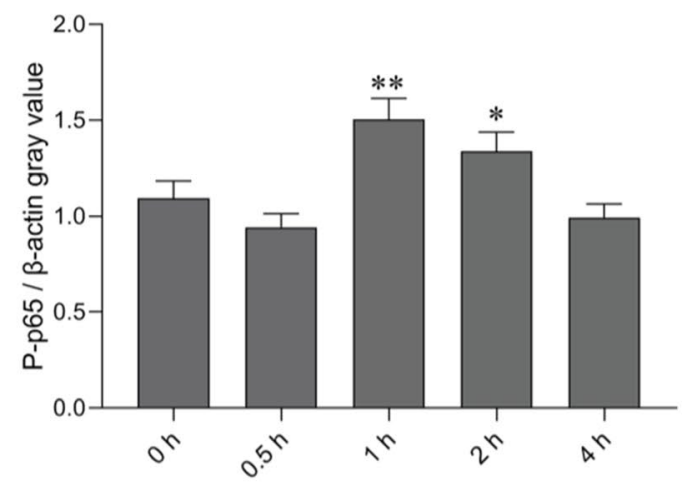

e

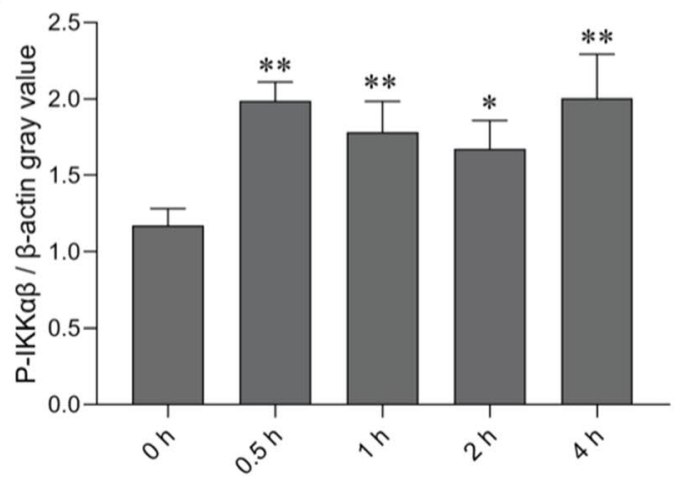

Fig. 4 NF-KB signaling pathway activation in response to GEV stimulation in mouse macrophages. a GEVs were inoculated into mouse macrophages previously coated onto coverslips for $1 \mathrm{~h}$, and immunofluorescence staining analysis of the subcellular location of NF-kB p65 was performed. Scale bars: $10 \mu \mathrm{m}$. b GEVs were inoculated into mouse macrophages, and cells were collected at the indicated time points for measurement of total protein and phosphorylated NF-KB p65, IKBa, IKKa and IKK $\beta$ protein expression levels by western blotting. c Gray value analysis of phospho-p65/ $\beta$-actin. d Gray value analysis of phospho-IKBa/ $\beta$-actin. e Gray value analysis of phospho-IKKaß/ $\beta$-actin. The results are shown as the mean \pm SEM of triplicate experiments. Significant differences vs 0-h control: ${ }^{*} p<0.05,{ }^{* *} p<0.01,{ }^{* * *} p<0.001$

anti-giardiasis drugs [29]. The innate immune system is involved in the development of various diseases through its recognition of PAMPs from pathogens. EVs carry pathogen-derived PAMPs to communicate with host cells and are involved in the innate immunity response [30]. Therefore, an in-depth study of the role of GEVs in the invasion of G. duodenalis into host cells and the underlying immune response mechanisms should contribute 


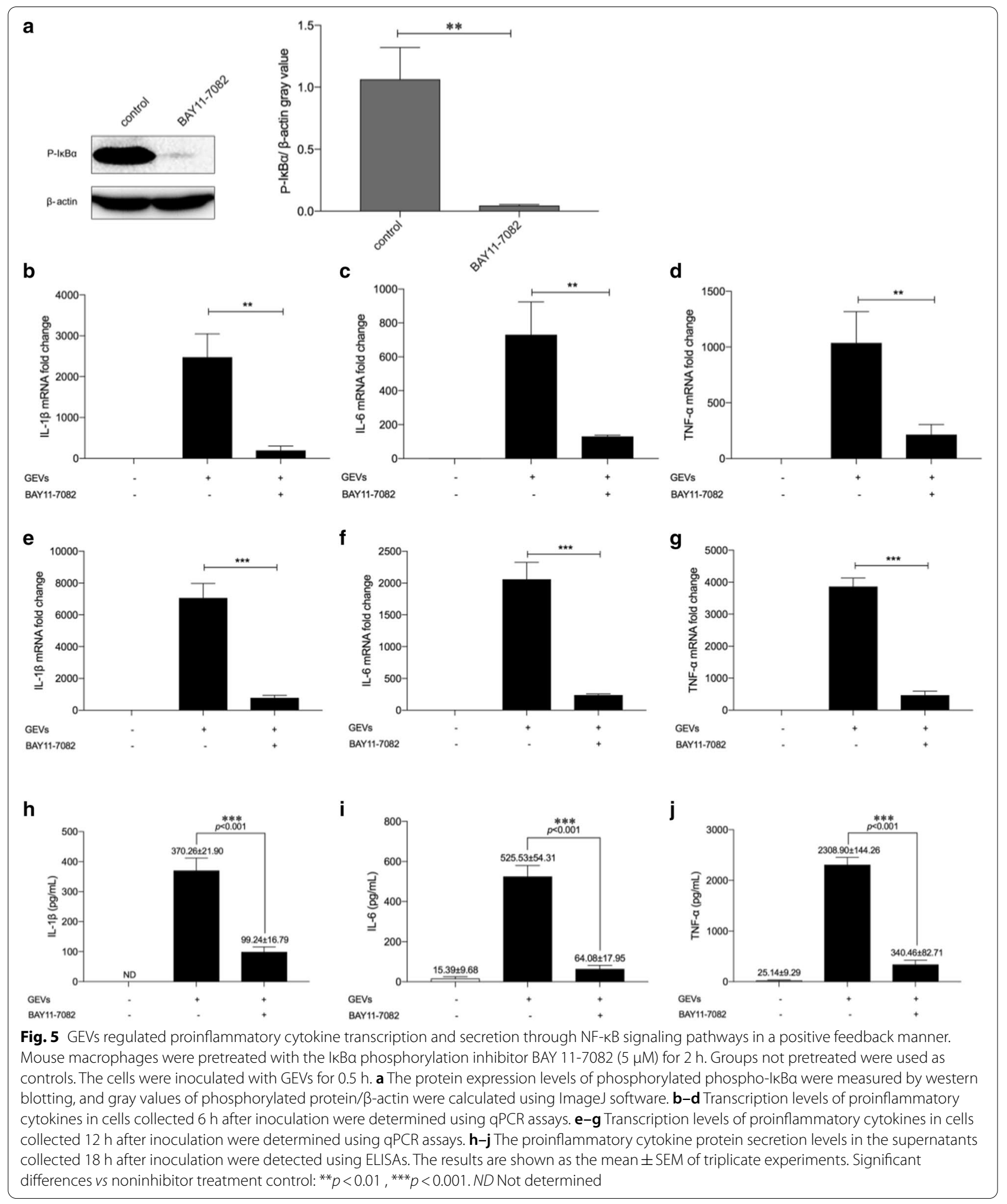


to a better knowledge of G. intestinalis-host interactions. Macrophages are the most important member of the innate immune system and play a vital role in resisting the invasion of multiple pathogens. In the present study, we examined the role of GEVs in the G. duodenalis-induced inflammatory response using mouse macrophages as models and determined the mechanisms by which GEVs trigger the inflammatory immune response.

Eukaryotic cells secrete EVs, which carry a cargo of biological molecules that mediate communication between cells [31]. Staphylococcus aureus-derived EVs increase the secretion of proinflammatory cytokines and $\mathrm{T}$ helper 2-biasing mediators, such as thymic stromal lymphopoietin, M1 inflammatory protein-1a and eotaxin production, all of which increase the number of eosinophils and enhance disease development [32]. Highly adherent strains of Trichomonas vaginalis release EVs that augment attachment to human cervical epithelial cells of poorly adherent strains [14]. Studies on G. duodenalis performed to date have generally focused on the role of EVs in the attachment of the parasite to intestinal epithelial cells, and few studies have examined the regulatory mechanisms of GEV-induced immune responses in hosts. Evans-Osses et al. reported that G. duodenalis microvesicles increased the activation and allostimulation of human dendritic cells $[16,17]$, and our recently published study showed that GEVs regulate host cell innate immunity via the TLR2 and NLRP3 inflammasome signaling pathways [20]. In the present study, we inoculated GEVs, G. duodenalis and GEVs + G. duodenalis into mouse macrophages and then measured the secretion levels of the proinflammatory cytokines IL-1 $\beta$, IL- 6 and TNF- $\alpha$. The results showed that both GEVs and $G$. duodenalis alone were able to trigger the production of these three proinflammatory cytokines and that GEV pretreatment enhanced the G. duodenalis-induced inflammatory response in mouse macrophages.

A previous study showed that inflammasome-derived IL-1 $\beta$ secretion induced IL-1R/MyD88 signaling to trigger nitric oxide production, which enabled the killing of parasites, such as Leishmania, Plasmodium and Toxoplasma gondii [33]. IL- 6 and TNF- $\alpha$ share of the ability to clear G. duodenalis in mouse infection models $[34,35]$. The enhanced levels of IL- $1 \beta$, IL- 6 and TNF- $\alpha$ triggered by GEVs may contribute to host resistance to disease development.

The MAPK signaling pathway regulates cell growth and differentiation and controls cellular responses to cytokines and stress [22]. The PI3K/Akt signaling pathway participates in cell survival or apoptosis [26]. The NF- $\mathrm{KB}$ signaling pathway is involved in the biological processes of immunity, inflammation and stress response [24]. Previous studies showed that extracellular products secreted by G. lamblia GS induced IL-8 secretion in HT-29 cells through activation of the p38, ERK and NF-kB pathways [36]. Mice deficient in TLR2 showed attenuation of giardiasis by increasing proinflammatory cytokine secretion, which was dependent on the AKT signaling pathway. In our present study, GEVs were inoculated into mouse macrophages, and total protein and phosphorylated protein levels of the MAPK, Akt and NF- $\mathrm{KB}$ signaling pathways were measured in infected cells $0,0.5,1,2$ and $4 \mathrm{~h}$ after inoculation. The results showed that GEVs phosphorylated p38 and ERK proteins, and inhibitory assays indicated that this process promoted proinflammatory cytokine secretion. GEVs also activated the AKT signaling pathway, and inhibition of AKT phosphorylation enhanced proinflammatory cytokine production. The inhibitory functions of AKT with MAPK were consistent with previously reported results that showed AKT negative feedback control of IL-12 production in dendritic cells [37]. NF- $\mathrm{kB}$ p65 is inhibited upon binding to I $\mathrm{I} B$ and remains inactive in the cytoplasm in classical signaling pathways. Stimulation with lipopolysaccharides, growth factors or antigen receptors activates the IKK complex (i.e. IKK $\beta$, IKK $\alpha$ and NEMO), which phosphorylates IкB. Phosphorylation of IкB triggers self-ubiquitination and degradation to cause the release of p65. After posttranslational modification, such as phosphorylation, acetylation or glycation, activated p65 is transported into the cell nucleus and induces gene expression, either alone or in combination with the transcription factors AP-1, ETs or Stat $[24,38]$. GEVs induced activation of the classical NF- $\mathrm{KB}$ signaling pathway through phosphorylation of ІкB $\alpha$, IKK $\alpha$ and IKK $\beta$ and translocation of NF- $\mathrm{kB}$ p65 into the nucleus in our study. Inhibition of $I \kappa B \alpha$ phosphorylation decreased GEV-induced inflammatory response levels in mouse macrophages.

\section{Conclusions}

The present study demonstrated that GEVs enhanced G. duodenalis-induced inflammatory response levels in mouse macrophages. Activation of the p38, ERK and NF- $\mathrm{kB}$ signaling pathways facilitated proinflammatory cytokine secretion and activation of the AKT signaling pathway to reduce proinflammatory cytokine production. The extensive research into the role of GEVs in regulating host cell inflammatory responses in vitro presented in this study provides data for exploring the underlying mechanisms in G. duodenalis-host interactions.

\section{Supplementary Information}

The online version contains supplementary material available at https://doi. org/10.1186/s13071-021-04865-5. 
Additional file 1: Figure S1. GEVs enhanced proinflammatory cytokines secretion from THP-1 cells. THP-1 cells were inoculated with $25 \mu \mathrm{g} / \mathrm{ml}$ GEVs, $1.5 \times 106$ G. duodenalis/ml, or GEVs combined with G. duodenalis (GEVS $+G$. duodenalis). ELISA measurements of the secretion levels of proinflammatory cytokines IL-1 $\beta$ (a), IL-6 (b) and TNF- $\alpha(\mathbf{c})$ in the supernatants collected $18 \mathrm{~h}$ after inoculation. The results are presented as the mean \pm standard error of the mean of triplicate experiments. Asterisks indicate significance level of difference vs the phosphate buffered saline control: ${ }^{*} p<0.05,{ }^{* *} p<0.01$, ${ }^{* * *} p<0.001$. Hashtag symbols indicate significance level of difference vs G. duodenalis-treated control: ${ }^{\#} p<0.05,{ }^{\# \#} p<0.01$. n.s. Not significant $(p>0.05)$.

\section{Acknowledgements}

The authors thank the National Science Foundation of China (No. 31772732 , 31101804 and No. 31672288) and the Fundamental Research Funds for the Central Universities for financial support. These agencies played no role in the study design, data collection and analysis, decision to publish, or preparation of the manuscript.

\section{Authors' contributions}

GP: Conceptualization, writing, review and editing of the manuscript; project administration; resources; and funding acquisition. ZP and CL: methodology, writing of the original draft, formal analysis and software and data curation. ZN, LJ, LX and LS: validation, formal analysis and investigation. WX, ZX and MS: data curation, visualization and supervision. All authors read and approved the final manuscript.

\section{Funding}

The authors thank the National Science Foundation of China (Nos. 31772732 31101804 and 31672288) and the Fundamental Research Funds for the Central Universities for financial support. These funding institutions played no role in the study design, data collection and analysis, decision to publish, or preparation of the manuscript.

\section{Availability of data and materials}

The data supporting the conclusions of this article are provided within the article. The original datasets analyzed in the present study are available from the corresponding author upon request.

\section{Declarations}

\section{Ethics approval and consent to participate}

Female C57BL/6 mice (6-8 weeks) were maintained under standard conditions in the animal house of the Laboratory Animal Center of Jilin University. The Animal Welfare and Research Ethics Committee of Jilin University approved all mouse experiments (IACUC Permit Number: pzpx20190929065).

\section{Consent for publication}

Not applicable.

\section{Competing interests}

The authors declare that they have no known competing financial interests or personal relationships that would appear to influence the work reported in this paper.

\begin{abstract}
Author details
'Key Laboratory of Zoonosis, College of Veterinary Medicine, Jilin University, Changchun 130062, People's Republic of China. ${ }^{2}$ Jilin Academy of Animal Husbandry and Veterinary Medicine, Changchun 130062, People's Republic of China. ${ }^{3}$ Jiangsu Key Laboratory of Marine Biological Resources and Environment, Jiangsu Key Laboratory of Marine Pharmaceutical Compound Screening, Co-Innovation Center of Jiangsu Marine Bio-Industry Technology, Jiangsu Ocean University, Lianyungang 222005, People's Republic of China.
\end{abstract}

Received: 14 May 2021 Accepted: 28 June 2021

Published online: 08 July 2021

\section{References}

1. Adam RD. Biology of Giardia lamblia. Clin Microbiol Rev. 2001;14:447-75.

2. Kotloff KL, Nataro JP, Blackwelder WC, Nasrin D, Farag TH, Panchalingam $\mathrm{S}$, et al. Burden and aetiology of diarrhoeal disease in infants and young children in developing countries (the Global Enteric Multicenter Study, GEMS): a prospective, case-control study. Lancet. 2013;382:209-22.

3. Leung AKC, Leung AAM, Wong AHC, Sergi CM, Kam JKM. Giardiasis: an overview. Recent Pat Inflamm Allergy Drug Discov. 2019;13:134-43.

4. Einarsson E, Ma'ayeh S, Svärd SG. An up-date on Giardia and giardiasis. Curr Opin Microbiol. 2016;34:47-52.

5. Savioli L, Smith H, Thompson A. Giardia and Cryptosporidium join the "neglected diseases initiative."Trends Parasitol. 2006;22:203-8.

6. Tkach $\mathrm{M}$, Théry $\mathrm{C}$. Communication by extracellular vesicles: where we are and where we need to go. Cell. 2016;164:1226-32.

7. Colombo M, Raposo G, Thery C. Biogenesis, secretion, and intercellular interactions of exosomes and other extracellular vesicles. Annu Rev Cell Dev Biol. 2014;30:255-89.

8. Poon IKH, Parkes MAF, Jiang L, Atkin-Smith GK, Tixeira R, Gregory CD, et al. Moving beyond size and phosphatidylserine exposure: evidence for a diversity of apoptotic cell-derived extracellular vesicles in vitro. J Extracell Vesicles. 2019;8:1608786.

9. Chen Z, Larregina AT, Morelli AE. Impact of extracellular vesicles on innate immunity. Curr Opin Organ Transplant. 2019;24:670-8.

10. Yáñez-Mó M, Siljander PR, Andreu Z, Zavec AB, Borràs FE, Buzas El, et al. Biological properties of extracellular vesicles and their physiological functions. J Extracell Vesicles. 2015;4:27066.

11. Dong G, Filho AL, Olivier M. Modulation of host-pathogen communication by extracellular vesicles (EVs) of the protozoan parasite Leishmania. Front Cell Infect Microbiol. 2019;9:100.

12. Hansen EP, Fromm B, Andersen SD, Marcilla A, Andersen KL, Borup A, et al. Exploration of extracellular vesicles from Ascaris suum provides evidence of parasite-host cross talk. J Extracell Vesicles. 2019;8:1578116.

13. Szempruch AJ, Sykes SE, Kieft R, Dennison L, Becker AC, Gartrell A, et al. Extracellular vesicles from Trypanosoma brucei mediate virulence factor transfer and cause host anemia. Cell. 2016;164:246-57.

14. Twu O, Miguel N, Lustig G, Stevens GC, Vashisht AA, Wohlschlegel JA, et al. Trichomonas vaginalis exosomes deliver cargo to host cells and mediate hostratioparasite interactions. PLoS Pathog. 2013;9:e1003482.

15. Zheng Y, Guo X, Su M, Guo A, Ding J, Yang J, et al. Regulatory effects of Echinococcus multilocularis extracellular vesicles on RAW264.7 macrophages. Vet Parasitol. 2017;235:29-36.

16. Evans-Osses I, Mojoli A, Monguió-Tortajada M, Marcilla A, Aran V, Amorim $\mathrm{M}$, et al. Microvesicles released from Giardia intestinalis disturb hostpathogen response in vitro. Eur J Cell Biol. 2017;96:131-42.

17. Gavinho B, Sabatke B, Feijoli V, Rossi IV, da Silva JM, Evans-Osses I, et al. Peptidylarginine deiminase inhibition abolishes the production of large extracellular vesicles from Giardia intestinalis, affecting host-pathogen interactions by hindering adhesion to host cells. Front Cell Infect Microbiol. 2020;10:417

18. Moyano S, Musso J, Feliziani C, Zamponi N, Frontera LS, Ropolo AS, et al. Exosome biogenesis in the protozoa parasite Giardia lamblia: a model of reduced interorganellar crosstalk. Cells. 2019;8:1600.

19. Wang XC, Gong PT, Zhang N, Li L, Chen SN, Jia LJ, et al. Inflammasome activation restrains the intracellular Neospora caninum proliferation in bovine macrophages. Vet Parasitol. 2019;268:16-20.

20. Zhao PP, Cao LL, Wang XC, Dong JQ, Zhang N, Li X, et al. Extracellular vesicles secreted by Giardia duodenalis regulate host cell innate immunity via TLR2 and NLRP3 inflammasome signaling pathways. PLoS Negl Trop Dis. 2021;15:e0009304.

21. Cobb MH. MAP kinase pathways. Prog Biophys Mol Biol. 1999;71:479-500.

22. Garrington TP, Johnson GL. Organization and regulation of mitogenactivated protein kinase signaling pathways. Curr Opin Cell Biol. 1999;11:211-8.

23. Lewis TS, Shapiro PS, Ahn NG. Signal transduction through MAP kinase cascades. Adv Cancer Res. 1998;74:49-139.

24. Perkins ND. Post-translational modifications regulating the activity and function of the nuclear factor kappa B pathway. Oncogene. 2006;25:6717-30.

25. Franke TF, Kaplan DR, Cantley LC. PI3K: downstream AKTion blocks apoptosis. Cell. 1997;88:435-7. 
26. Franke TF, Yang SI, Chan TO, Datta K, Kazlauskas A, Morrison DK, et al. The protein kinase encoded by the Akt proto-oncogene is a target of the PDGF-activated phosphatidylinositol 3-kinase. Cell. 1995;81:727-36.

27. Li S, Gong PT, Tai LX, Li X, Wang XC, Zhao CY, et al. Extracellular vesicles secreted by Neospora caninum are recognized by toll-Like teceptor 2 and modulate host cell innate immunity through the MAPK signaling pathway. Front Immunol. 2018;9:1633.

28. Li X, Zhang XC, Gong PT, Xia FF, Li L, Yang ZT, et al. TLR2 $\%$ mice display decreased severity of giardiasis via enhanced proinflammatory cytokines production dependent on AKT signal pathway. Front Immunol. 2017:8:1186.

29. Ansell BRE, McConville MJ, Ma'ayeh SY, Dagley MJ, Gasser RB, Svärd SG, et al. Drug resistance in Giardia duodenalis. Biotechnol Adv. 2015;33:888-901.

30. Twu O, Miguel N, Lustig G, Stevens GC, Vashisht AA, Wohlschlegel JA, et al. Trichomonas vaginalis exosomes deliver cargo to host cells and mediate hostratioparasite interactions. PLoS Pathog. 2013;9:e1003482.

31. Macia L, Nanan R, Hosseini-Beheshti E, Grau GE. Host- and microbiotaderived extracellular vesicles, immune function, and disease development. Int J Mol Sci. 2019:21:107.

32. Hong SW, Kim MR, Lee EY, Kim JH, Kim YS, Jeon SG, et al. Extracellular vesicles derived from Staphylococcus aureus induce atopic dermatitis-like skin inflammation. Allergy. 2011;66:351-9.

33. de Carvalho RVH, Zamboni DS. Inflammasome activation in response to intracellular protozoan parasites. Trends Parasitol. 2020;36:459-72.
34. Zhou P, Li E, Zhu N, Robertson J, Nash T, Singer SM. Role of interleukin-6 in the control of acute and chronic Giardia lamblia infections in mice. Infect Immun. 2003;71:1566-8.

35. Zhou P, Li E, Shea-Donohue T, Singer SM. Tumour necrosis factor a contributes to protection against Giardia lamblia infection in mice. Parasite Immunol. 2007;29:367-74.

36. Lee HY, Hyung S, Lee NY, Yong TS, Han SH, Park SJ. Excretory-secretory products of Giardia lamblia induce interleukin-8 production in human colonic cells via activation of p38, ERK1/2, NF-kappaB and AP-1. Parasite Immunol. 2012;34:183-98.

37. Fukao T, Tanabe M, Terauchi Y, Ota T, Matsuda S, Asano T, et al. PI3Kmediated negative feedback regulation of IL-12 production in DCs. Nat Immunol. 2002;3:875-81.

38. Chen J, Chen ZJ. Regulation of NF-kB by ubiquitination. Curr Opin Immunol. 2013;25:4-12.

\section{Publisher's Note}

Springer Nature remains neutral with regard to jurisdictional claims in published maps and institutional affiliations.
Ready to submit your research? Choose BMC and benefit from:

- fast, convenient online submission

- thorough peer review by experienced researchers in your field

- rapid publication on acceptance

- support for research data, including large and complex data types

- gold Open Access which fosters wider collaboration and increased citations

- maximum visibility for your research: over 100M website views per year

At BMC, research is always in progress.

Learn more biomedcentral.com/submissions 